\title{
KRZYSZTOF W. OPALIŃSKI ${ }^{1}$
}

\section{Competition for food in macroplankton animals in the Vistula Lagoon}

\author{
In memory of Professor Krystyna Maciejewska
}

Key words: interspecific competition, early developmental stages of fish species, Vistula Lagoon

\section{Summary}

Competition for food can be observed in the macroplankton community in the Vistula Lagoon (northern Poland) in the spring (April-May-June). This is the time of mass occurrence of early developmental stages of the Baltic Sea herring, the European smelt, perch, and stickleback. Additionally, some quantities of the shrimp Neomysis integer can be found. These species use the same food resources, i.e. small zooplankton, but they occupy different habitats. However, in a very special situation in the Vistula Lagoon (low depth and water mixing by winds) they are living together and compete for food. The purpose of this paper is to find out which species is the superior competitor for food among the macroplankton living in the Vistula Lagoon. Animal size (dry weight $D w$ ), daily consumption rate $(C)$, and coefficients of food assimilation efficiency $\left(U^{-1}\right)$, as well as utilization of consumed energy for growth $\left(K_{1}\right)$, and utilization of assimilated energy for growth $\left(K_{2}\right)$ by individuals of particular species were used as measures of individual success in competition for food. Animal abundance $\left(n \mathrm{~m}^{-3}\right)$, daily consumption rate of individuals of particular species living in the unit of water volume $\left(\mathrm{J} \mathrm{m}^{-3}\right.$ $\mathrm{d}^{-1}$ ), and total food consumed by animals of particular species living in the unit of water volume as a percent of the total food available were used as

1 Cardinal Stefan Wyszyński University in Warsaw, Institute of Ecology and Bioethics, Wóycickiego 1/3, 01-938 Warsaw, Poland, e-mail: k.opalinski@uksw.edu. $\mathrm{pl}$ 
measures of population (or species) success in competition for food. The results do not provide a clear indication which species is a superior competitor for food. Because competition occurs at the level of individuals rather than populations, a question arises why just Neomysis, despite their lowest food consumption and the lowest daily production rate succeeded in reaching high population numbers and sum of daily food consumption by population.

\section{Introduction}

\subsection{Interspecific interactions}

Eugene Pleasants Odum (1971) in his book Fundamentals of Ecology describes a number of possible interspecific interactions that link the species of a community. Interspecific interactions can be symbolized by the positive (+) or negative (-) effects of the interaction on the individual species. 0 (null) indicates that a population is not affected by the interaction.

Odum's types of interspecific interactions are:

- neutralism - an interaction in which one species neither harms nor helps the other one $(0 / 0)$;

- interspecific competition - an interaction occurring when species compete for a specific limiting resource. When two species compete for a resource, the result is detrimental (negative) to both of them (-/-);

- predation - the interaction between species in which one species, the predator, injures or kills and eats the other, the prey (+/-);

- parasitism - a symbiotic interaction in which a parasite derives its nourishment from a host, which is harmed in the process $(+/-)$;

- mutualism - an interspecific symbiosis in which two species benefit from their interaction $(+/+)$. Examples of mutualism include nitrogen fixation by bacteria in the root nodules of legumes, digestion of cellulose by microorganisms in the guts of ruminant mammals, and the exchange of nutrients in mycorrhizae, the association of fungi and plant roots; 
- commensalism - an interaction that benefits one species but neither harms nor helps the other (+/0). Commensal interactions are difficult to document in nature because any close association between species likely affects both species, if only slightly.

\subsection{What is interspecific competition?}

Interspecific competition can occur when species compete for a specific limiting resource. When two species compete for a resource, the result is detrimental (negative) to both species (-/-). Strong competition can lead to the local elimination of one of the two competing species, a process called competitive exclusion. The competitive exclusion principle states that two species with similar needs for the same limiting resources cannot coexist in the same place.

The term competitive exclusion was used for the first time by Russian biologist Georgii Frantsevich Gause (1932) in his paper Experimental Studies on the Struggle for Existence. Gause wrote that two species with similar ecological niches cannot coexist in a stable equilibrium, meaning that when two species compete for exactly the same requirements, one will be slightly more efficient than the other and will reproduce at a higher rate as a result. The fate of the less efficient species is local extinction.

\subsection{Does competition occur?}

The way competition influence species distribution across environments, their relative abundance and diversity were central issues of the debate on the importance of competition of the 1970s and 1980s (Salt 1984, Strong et al. 1984, Diamond and Case 1986). Conell (1975) concluded that most of the data on competition were observational or performed in a laboratory, and that predation, rather than competition is the predominant ecological interaction between species. Schoener (1983), after reviewing the field experiments on interspecific competition, concluded that interspecific competition is the most common kind of interaction among organisms under 
natural conditions. He calculated that in 64 field experiments with animals, 90\% demonstrated the existence of interspecific competition. Goldberg and Barton (1992) calculated that in 101 field experiments with vegetables (quantitative only) 63\% of the results demonstrated significant effects of interspecific competition on the distribution patterns, relative abundance, diversity, and community structure. Therefore, the skepticism concerning the existence of interspecific competition in nature can be rejected (Schoener 1983).

But Odum (1992) in his Great Ideas in Ecology for the 1990s listed the top 20 greatest hits of ecology, and the eighth hit is "Competition may lead to diversity rather than to extinction. Competition plays a major role in shaping the species composition of biotic communities. But competitive exclusion in which one species eliminates another is probably the exception rather than the rule in open systems of nature. Species are often able to shift their functional niche to avoid the deleterious effects of competition."

\section{4. Mechanism of competition}

Traditionally, interspecific competition or generally - competition is divided into two classes:

- exploitative, in which individuals, by using resources, deprive others of benefits to be gained from the resources;

- interference competition, when individuals harm one another by fighting, producing toxins, etc.

Schoener (1983) used six kinds of competition which describe more exactly mechanisms of competition: consumptive, preemptive, overgrowth, chemical, territorial and encounter.

Schoener's consumptive competition clearly lies within traditional exploitative competition, and occurs when some quantity of resources (e.g. food) is consumed by an individual, thereby depriving other individuals of it. 


\subsection{How to measure results of interspecific competition?}

When two species compete for exactly the same requirements, one will be slightly more efficient than the other and will reproduce at a higher rate as a result. The fate of the less efficient species is local extinction. This better reproduction and local extinction can be measured as changes in distribution patterns - relative abundance, diversity, and community structure (Goldberg and Barton 1992). For measuring such an effect, field experiments must be done (manipulations of the abundance of one hypothetically competing species: introductions, removals, etc.) (Schroere 1983).

Another way is the bioenergetic method: measurements of the effect of the Schoener's consumptive competition, i.e., measuring the quantity of food eaten by competing species.

\subsection{The aim}

Consumptive (or scramble - see Grimm and Railsback 2005) competition can be observed in the macroplankton community in the Vistula Lagoon (northern Poland) during spring (April-MayJune). This is the time of mass occurrence of early developmental stages of the Baltic Sea herring, European smelt, perch, and stickleback. (Naumenko1998, Krassovskaya 1998, 2002). Some quantity of the shrimp Neomysis integer can be observed. These species use the same food resources - small zooplankton. First, these are small rotifers (Keratella cochlearis, K. quadrata, Filinia longiseta, Brachionus angularis, and Hexarthra fennica - see Opaliński et al. 2004). As all early developmental stages of fish species appear in the Lagoon approximately at the same time and the abundance of zooplankton is limited (not only by predation but also by succession), they compete for food. Usually populations of perch, stickleback, herring, smelt, and Neomysis use different habitats, but in the Vistula Lagoon, the situation is very special: low depth $(2.7 \mathrm{~m})$, and water mixing by winds (see e.g. Chubarenko and Margoński 2008) make space segregation 
of macroplankton species impossible - they are living together and they compete for food.

The purpose of this paper is to find out which species is the superior competitor for food among the macroplankton species living in the Vistula Lagoon. Animal size (dry weight $D w$ ), daily consumption rate $(C)$, and coefficients of food assimilation efficiency $\left(U^{-1}\right)$, utilization of consumed energy for growth $\left(K_{1}\right)$, and utilization of assimilated energy for growth $\left(K_{2}\right)$ (sensu Duncan and Klekowski, 1975) by individuals of particular species were used as measures of individual success in competition for food. Animal abundance $\left(n \mathrm{~m}^{-3}\right)$, daily consumption rate of individuals of particular species living in the unit of water volume $\left(\mathrm{J} \mathrm{m}^{-3} \mathrm{~d}^{-1}\right)$, and total food eaten by animals of particular species living in the unit of water volume as a percent of the total food available were used as measures of population (or species) success in competition for food.

Daily consumption rate $(C)$ and both coefficients $\left(U^{-1}\right.$ and $\left.K_{2}\right)$ were calculated using data on production $(P)$, respiration $(R)$, egestion $(F)$, and excretion $(U)$ of animals.

\section{Material and methods}

\subsection{Animals}

As potential competitors, early developmental stages of four fish species were examined from the Vistula Lagoon (south Baltic Sea): Baltic Sea herring (Clupea harengus membras, Linnaeus, 1758), European smelt (Osmerus eperlanus Linnaeus, 1758, which are sympatric in the Lagoon and which are putative competitors), perch (Perca fluviatilis Linnaeus, 1758), stickleback (Gasterosetus aculeatus Linnaeus, 1758, which use other habitats than herring and smelt, but in early summer they eat the same food sources as herring and smelt). The fifth species there is opossum shrimp Neomysis integer (Leach 1814).

Animals were caught in the $1.5-\mathrm{m}$ surface layer of the southern part of the Vistula Lagoon, close to the harbor in Tolkmicko, where the depth is ca. $2 \mathrm{~m}$. The water salinity in this place was $2.5 \mathrm{PSU}$. The 
catches were carried out from a boat using $5 \mathrm{~m}$ long "Neuston" type plankton net with $500 \mu \mathrm{m}$ mesh and $2 \mathrm{~m}^{2}$ opening. After landing the net, the fish were transferred to thermoses with aerated water and then transported to the laboratory, and after some hours (adaptation time) the animals were placed into the respiratory vessels.

\subsection{Procedures}

All procedures (measurements of oxygen consumption and ammonia excretion rates, expositions for measuring defecation rate) were carried out in the natural sea water from the Lagoon in the thermostats with temperature of $12^{\circ} \mathrm{C}$ and salinity $2.5 \mathrm{PSU}$.

Consumption or daily food ration or daily energy requirement $(C)$ of an animal was calculated from the equation $C=P+R+F+U$, (Duncan and Klekowski 1975), where $P$ - production, $R$ - respiration, $F$ - egestion, and $U$ - excretion. Parameters $P, R, U$ and $F$ were measured as follows:

Production $(P)$. The increase in the average dry weight $(D w)$ of animals was considered as their biological production. Therefore body mass production in animals was determined as an average increase in the dry weights of particular individuals in three to five day period.

After the exposition for growth rate, animals were killed with formaldehyde, their standard body length $(L C)$ was measured immediately to the nearest $0.01 \mathrm{~mm}$ and wet weight to the nearest 0.5 $\mathrm{mg}$. Then the animals were dried at $60^{\circ} \mathrm{C}$ to a constant weight and weighed (dry weight to the nearest $0.01 \mathrm{mg}$ ).

Metabolic rate (oxygen consumption rate $R$ ). The respiration of animals was determined by the closed vessel method at the temperature of their natural environment. Respirometric vessels $100 \mathrm{~cm}^{3}$ in volume were used. Exposure time of individual animals in respirometers was 2 to 3 hours. The oxygen concentration was measured using an oxygen sensor (OXI 3000 by WTW). Unfiltered sea water with natural plankton as food, and four respirometers without animals as a control were used (see Klekowski et al. 1980, Maciejewska et al. 2001, Maciejewska and Opaliński 2002, Opaliński et al. 2004). 
Because animals could swim and eat in the respirometric vessels, the measured metabolism can be defined as the routine one sensu Fry $(1947,1957)$. After the oxygen consumption measurements, the animals were killed with formaldehyde and their standard body length; wet and dry weights were measured immediately.

Excretion $(U)$. After the measurement of oxygen concentration, ammonia concentration was determined in the same water volume using the indo-phenol method (Solorzano 1969).

Egestion $(F)$. The quantity of feces produced by the fish was determined by weight. Five specimens were placed in glass aquaria with one liter of water. After 24 hours of exposure, the water was passed through glass filters and the deposit obtained was assumed to be the excrements of the specimens. The same aquarium setup without specimens served as the control (five control aquaria were used). The filters were dried at a temperature of $60^{\circ} \mathrm{C}$ (to constant weight), and then they were weighted. The amount of feces was expressed in $\mathrm{mg}$ of dry weight per specimen per day. Because during the exposure time a portion of the mass of the fecal pellets was leached into the water, $28 \%$ was added to the mass of the measured amount of egested feces (Maciejewska and Opaliński 2002).

Consumption $(C)$. Daily food rations were calculated after the conversion of all parameters into energy units. The energy content of consumption (food), production (body mass), and egesta (feces) was measured. The energy equivalent of ammonia (0.349 J micro- mole $^{-1}$ ) was taken from Elliott and Davison (1975), and of oxygen consumption (0.0197 $\mathrm{J} \mathrm{mm}^{-3}$ ) from Kleiber (1961).

Energy value. Energy content of the food, body mass, and egesta was calculated on the basis of its elementary composition. Elementary composition was analyzed in homogenized and pelleted material. Percentage analysis of the carbon, nitrogen and hydrogen contents in the material was done in a gas chromatograph CHN-S by Carlo Erba. Oxygen content was calculated as the difference: $\mathrm{O}_{2} \%=100 \%-(\mathrm{C} \%$ $+\mathrm{H} \%+\mathrm{N} \%+\mathrm{S} \%+$ ash\%), and the ash content in the sample being known (Bieńkowski 1990). Ash content was measured gravimetrically after burning the sample at $450^{\circ} \mathrm{C}$ (Dowgiałło 1975). Energy value (Ev) 
of the material was calculated using Dulong's formula $\left(E v\right.$ in $\operatorname{Jmg} D w^{-1}$ $=0.004184 \times(82 \times \%$ of carbon $+292.69 \times \%$ of hydrogen $-0.25 \times \%$ of oxygen $+25 \mathrm{x} \%$ of sulphur) (Colombo et al. 1988, Bieńkowski 1990, Kamler 2003).

\section{Results}

\subsection{Case study - herring}

Production $(P)$

The production rate of herring was performed in natural conditions - fish were caught on May 12 and May 15. The increase in the mean dry weight of specimens was regarded as their biological production (Fig.1). The average dry weight on May 12 was $3.60 \mathrm{mg}$, and after three days it was 4. 38. Daily biological production was 0.26 $\mathrm{mg} D w$ ind $^{-1} \mathrm{~d}^{-1}$ and $0.07 \mathrm{mg} D w \mathrm{mg} D w^{-1} \mathrm{~d}^{-1}$. Fifty four animals were used with dry weights of $2.60-4.30 \mathrm{mg}$.

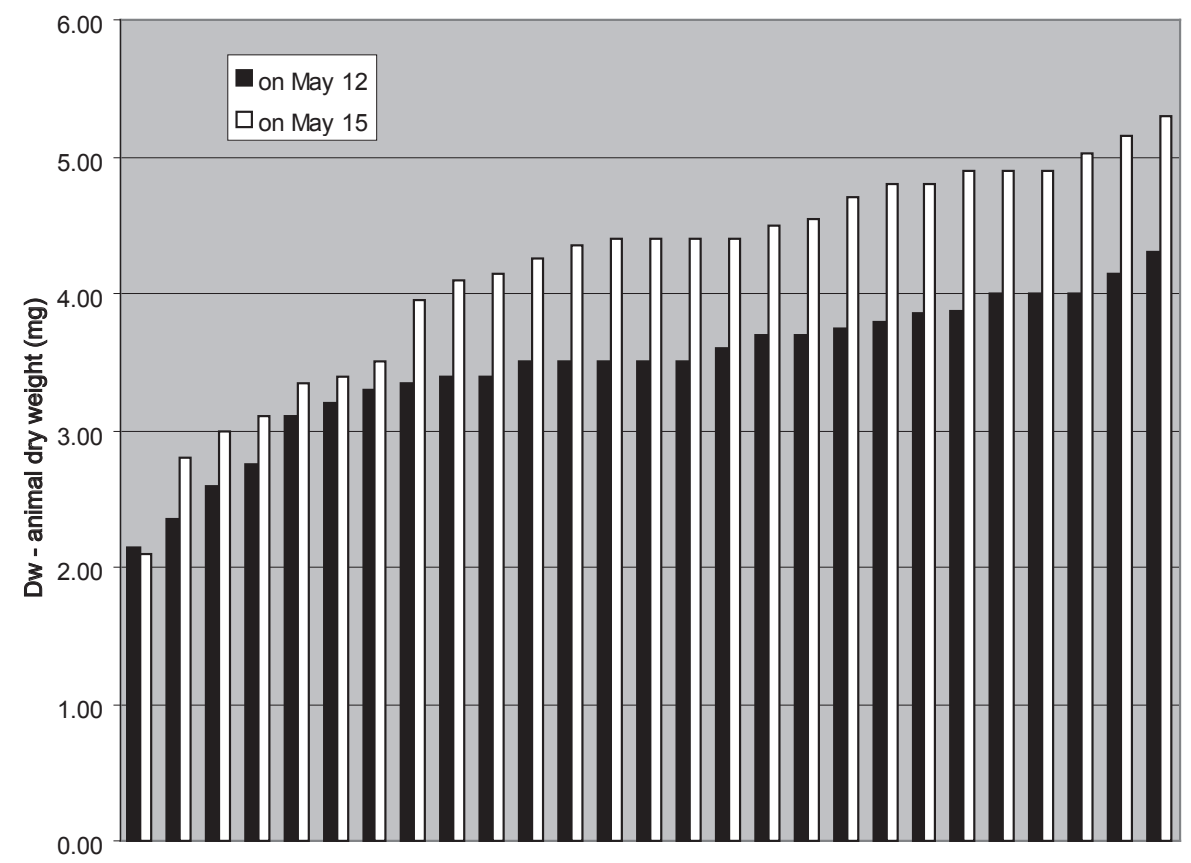

Fig. 1. Dry weight of herrings on May 12 and on May 15: average daily biological production was $0.26 \mathrm{mg} D w$ ind $^{-1} \mathrm{~d}^{-1}$ and $0.07 \mathrm{mg} D w \mathrm{mg} D w^{-1} \mathrm{~d}^{-1}$. 
Respiration (oxygen consumption $R$ )

Ninety measurements of oxygen consumption of herring larvae and fry with dry weight of $2.10-5.30 \mathrm{mg}$ were done. The dependence between animal dry weight $(D w)$ and its oxygen consumption $(R)$ was calculated: $R=7.5 D w^{0.72}$ (Fig. 2), thus oxygen consumption of an average animal with the dry weight of $3.60 \mathrm{mgDw}$ was equal to $18.86 \mathrm{~mm}^{3}$ ind $^{-1} \mathrm{~h}^{-1}$. There were $5.24 \mathrm{~mm}^{3} \mathrm{mgDw} w^{-1} \mathrm{~h}^{-1}$ and $126 \mathrm{~mm}^{3}$ $\operatorname{mg} D w^{-1} \mathrm{~d}^{-1}$.

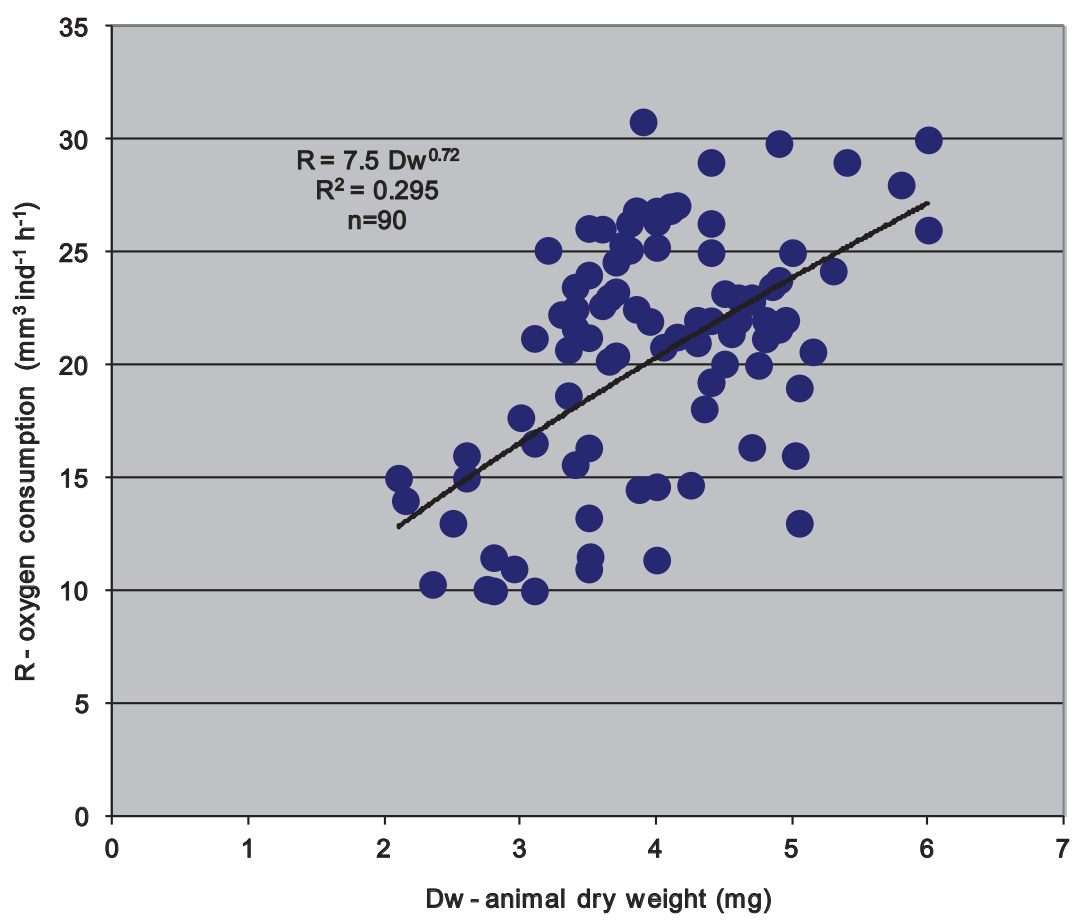

Fig. 2. The dependence between oxygen consumption $R$ and animal dry weight $D w$ in herrings. General dependence: $R=a D w^{b}$.

Egestion (feces production $F$ )

Sixteen measurements of feces production of herring juvenile stages were done. The dependence between animal dry weight $(D w)$ and dry weight of egesta production per day $(F)$ was calculated: $F=$ $0.67 D w^{0.78}$ (Fig. 3). Feces production of an animal with dry weight of 
$3.60 \mathrm{mg}$ was equal to $1.82 \mathrm{mg} D w$ per individual per day $(0.51 \mathrm{mg} D w$ $\left.\mathrm{mg} D w^{-1} \mathrm{~d}^{-1}\right)$.

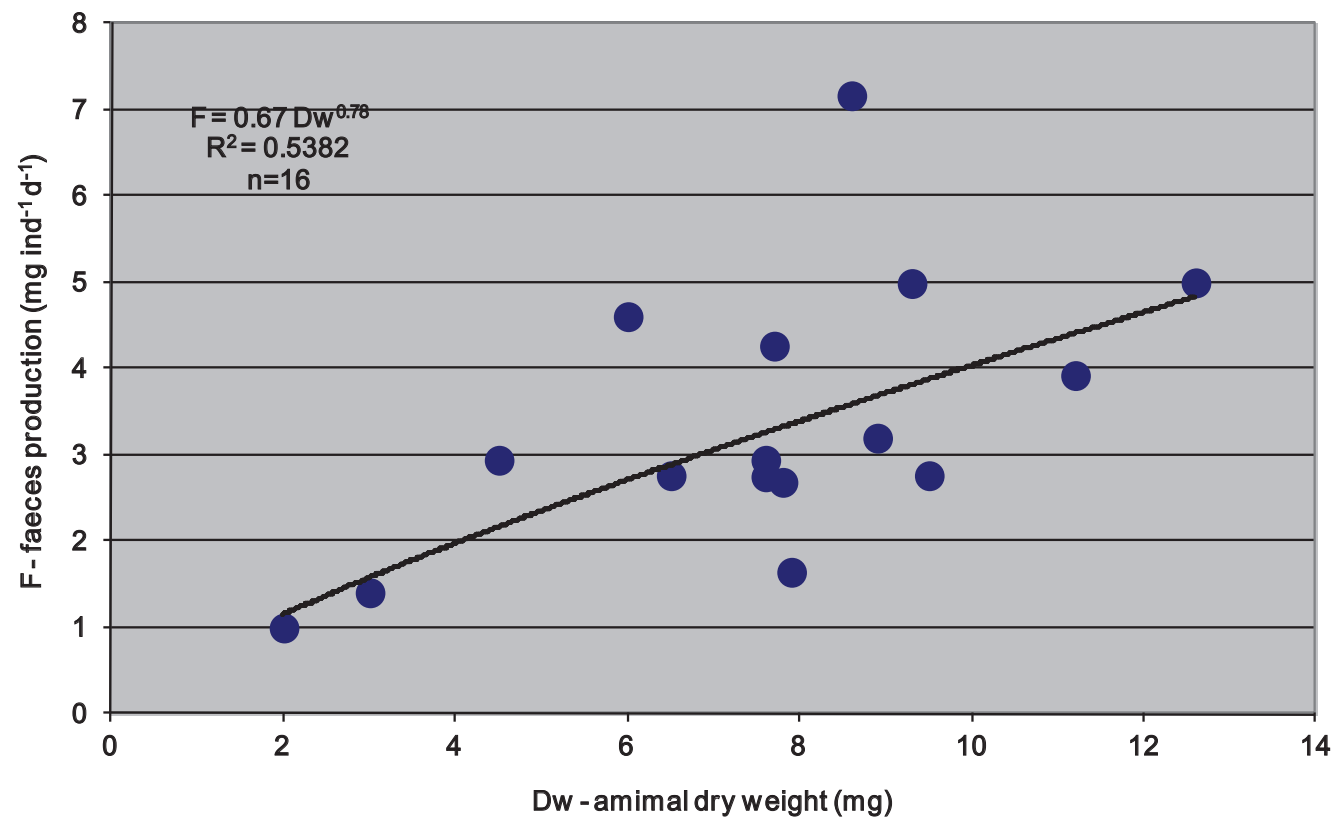

Fig. 3. The dependence between feces production $F$ and animal dry weight $D w$ in herrings. General dependence: $F=a D w^{b}$.

Excretion (ammonia production $U$ )

Eleven measurements of excretion rate (ammonia production) were made. The dependence between animal dry weight $(D w)$ and excretion $(U)$ was calculated: $U=0.16 D w^{0.66}$ (Fig. 4), thus ammonia excretion by an average animal with a dry weight of $3.60 \mathrm{mg}$ was 0.37

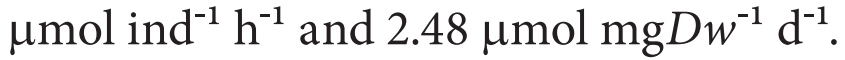




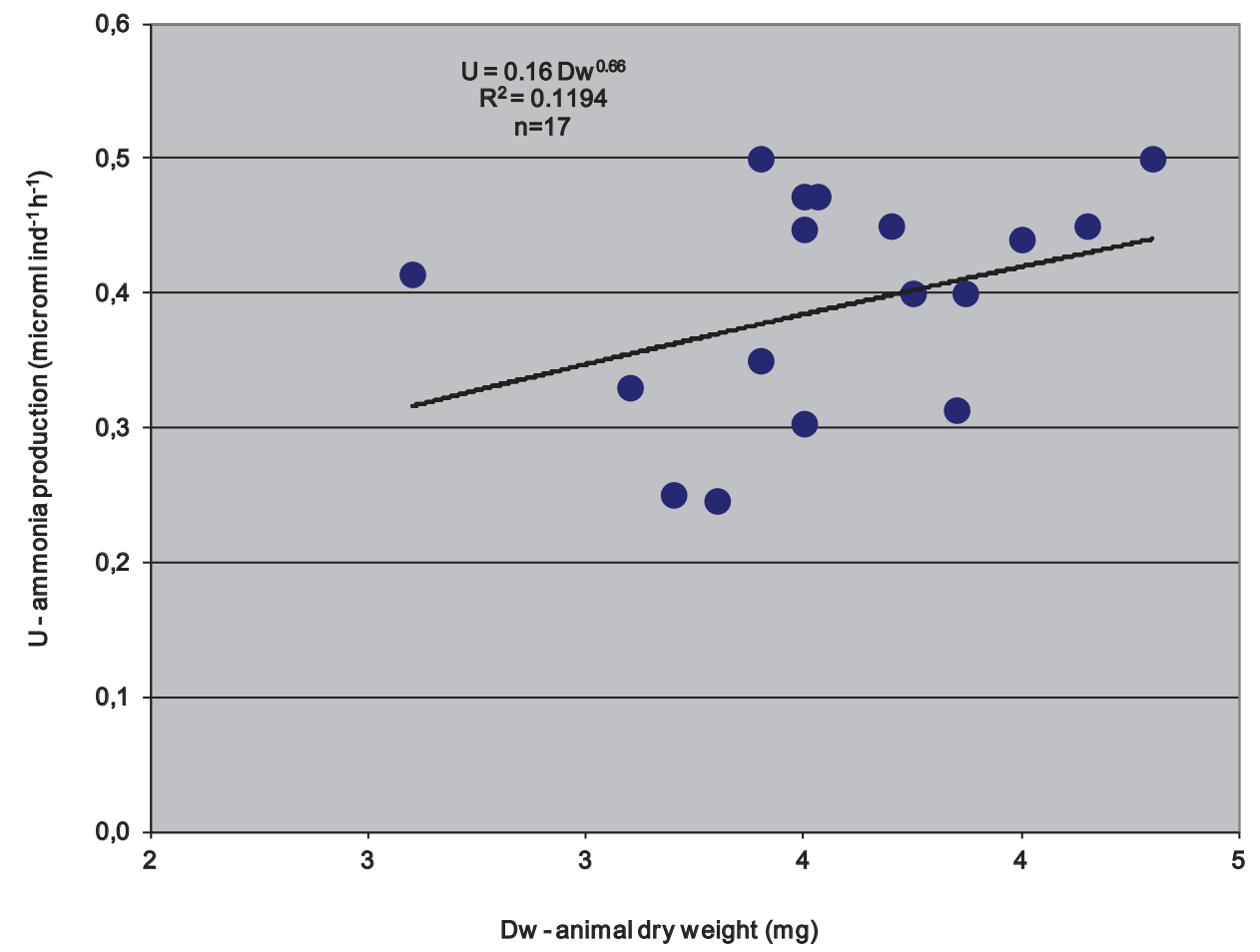

Fig. 4. The dependence between ammonia production $U$ and animal dry weight $D w$ in herrings. General dependence: $U=a D w^{b}$.

Elemental composition and energetic value

Elemental composition of herring larvae $(P)$, its food $(C)$, and feces $(F)$ were measured (Fig. 5) and energetic value of these parameters was calculated from Dulong's formula: $P=26.4 \mathrm{~J} \mathrm{mgDw}^{-1}, C=26.5 \mathrm{~J}$ $\mathrm{mg} D w^{-1}, F=26.3 \mathrm{~J} \mathrm{mg} D w^{-1}$. 


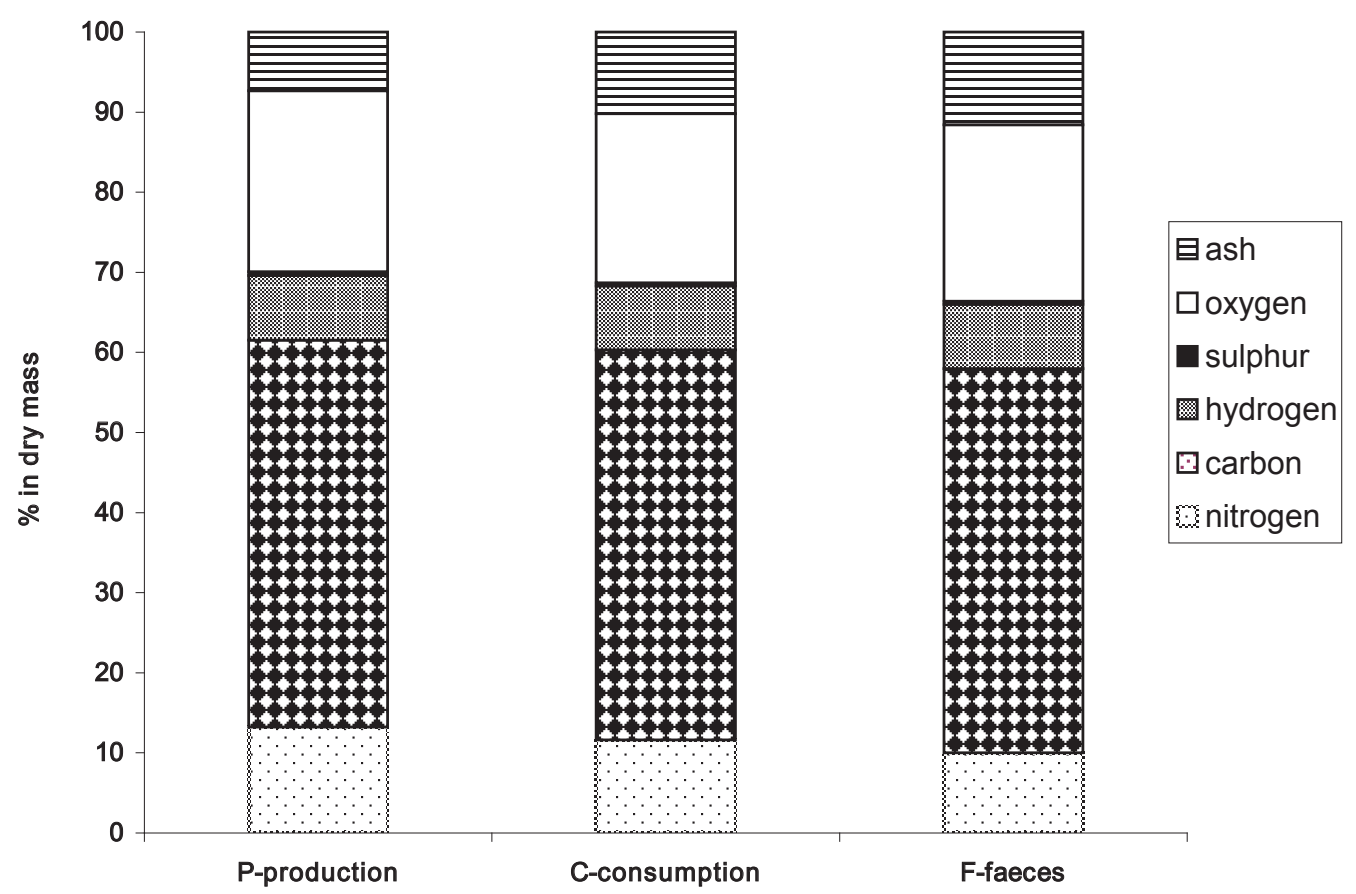

Fig. 5. Element composition of herring's body (production $P$ ), its food (consumption C) and feces $(F)$

Consumption (daily energy requirement $C$ )

Consumption (daily energy requirement) was calculated after con-

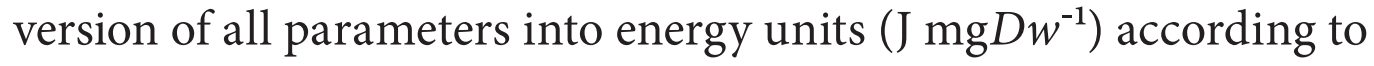
the equation: $C=P+R+U+F$. The energy equivalent of ammonia $(0.349$ $\mathrm{J} \mathrm{mmole}^{-1}$ ) was taken from Elliott, Davison (1975), and of oxygen consumption $\left(0.0197 \mathrm{~J} \mathrm{~mm}^{-3}\right.$ ) from Kleiber (1961).

\subsection{Competition for food in macroplankton animals}

\subsubsection{Individual level}

In the same way, like for herring, measurements and calculations were done for other macroplankton species dominating in the Vistula Lagoon pelagial zone in the spring season: Neomysis, smelt, stickleback, and perch. 
Animal size (dry weight $D w$ ), daily consumption rate $(C)$ and production rate $(P)$, coefficients of food assimilation efficiency $\left(U^{-1}\right)$, utilization of consumed energy for growth $\left(K_{1}\right)$, and utilization of assimilated energy for growth $\left(K_{2}\right)$ by individuals of particular species were used as measures of individual success in competition for food.

In May 2004, the highest size (dry weight) was observed in smelt, the next highest in stickleback, then in Neomysis, herring, and perch (Fig. 6). The highest food ration was consumed by stickleback, followed by smelt, herring, perch, and Neomysis (Fig. 7). The highest daily production rate was observed in smelt, followed by stickleback, herring, perch, and Neomysis (Fig. 7).

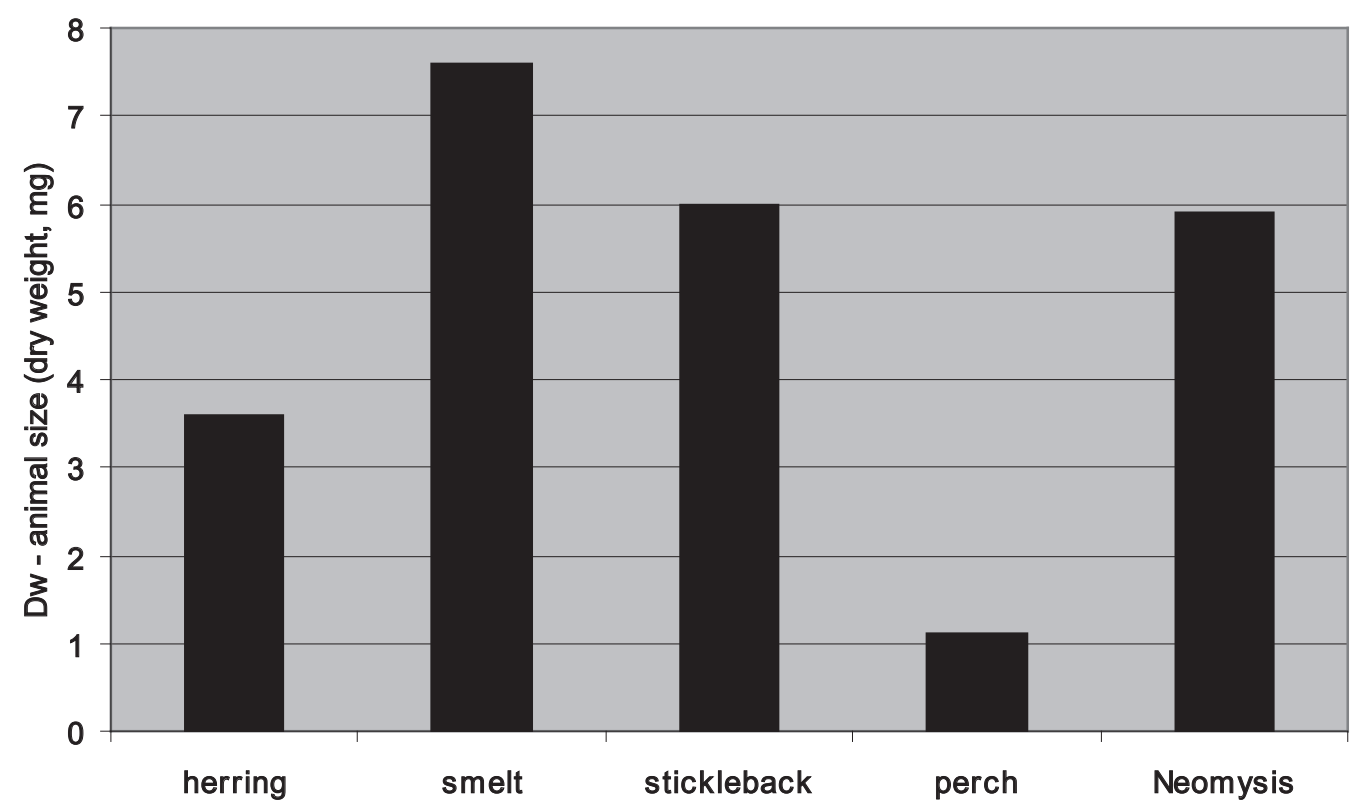

Fig. 6. Size (animal dry weight) of plankton animals in Vistula Lagoon in spring. 


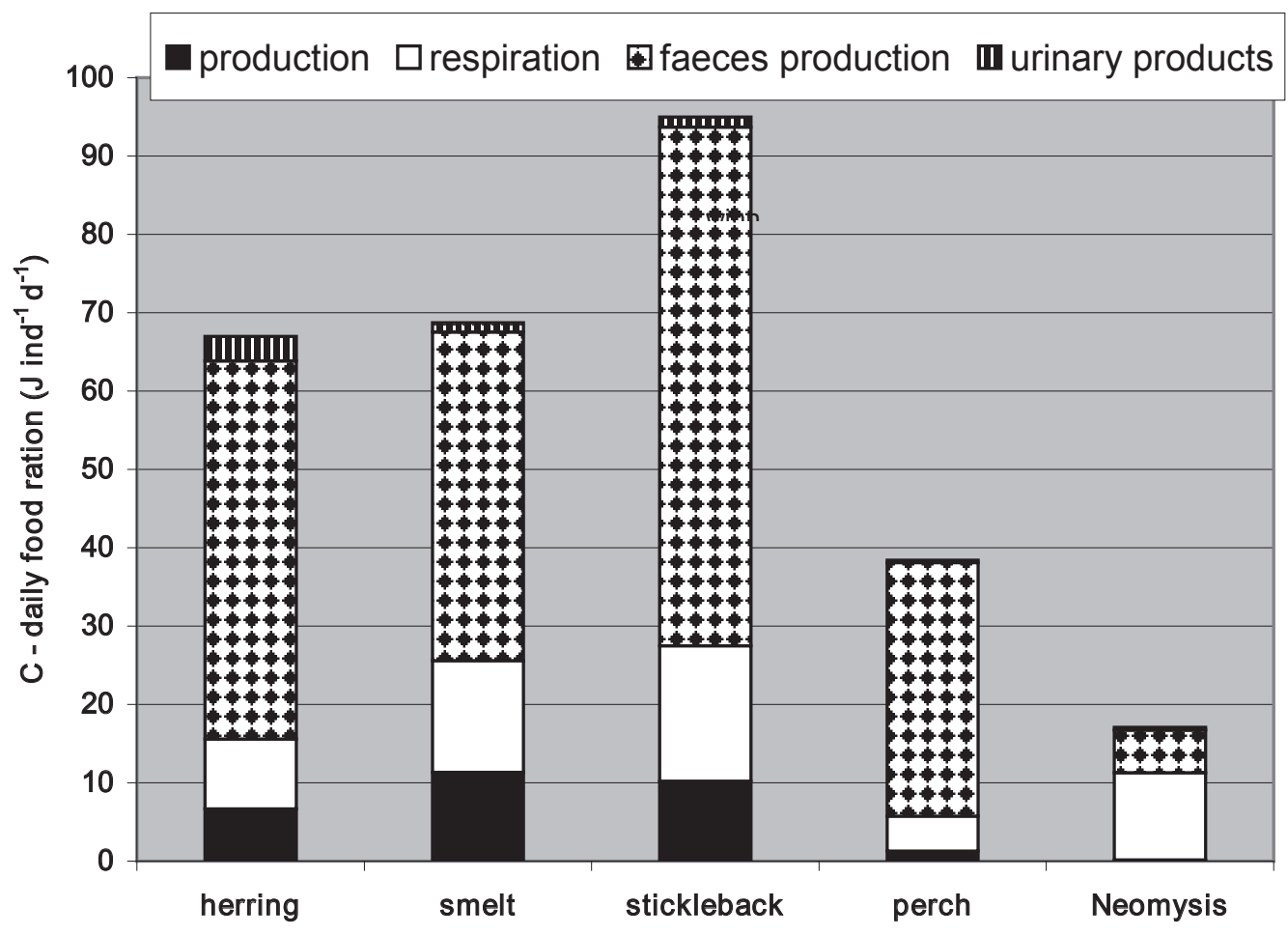

Fig. 7. Daily food ration $(C)$ as a sum of production, respiration, feces production, and urinary products in macroplankton animals in the Vistula Lagoon in spring. Stickleback has the highest daily food ration $(C)$ and smelt has highest daily production ration.

The highest food assimilation efficiency (coefficient $U^{-1}$ ) was observed in Neomysis, the highest utilization of food for growth (coefficient $\left.K_{1}\right)$ and assimilated food for growth $\left(K_{2}\right)$ were observed in smelt (Fig. 8).

If each first place in competition in any given discipline $(D w, C$, $\left.U^{-1}, K_{1}, K_{2}\right)$ is assigned 5 points, the second 4 points, the third 3 points, the fourth 2 points, and the last one 1 point, then the winner in competition for food at the individual level will be smelt (28 points of 30 possible), followed by stickleback, herring, Neomysis, and perch (Fig. 9). Smelt is the superior competitor at individual level. 


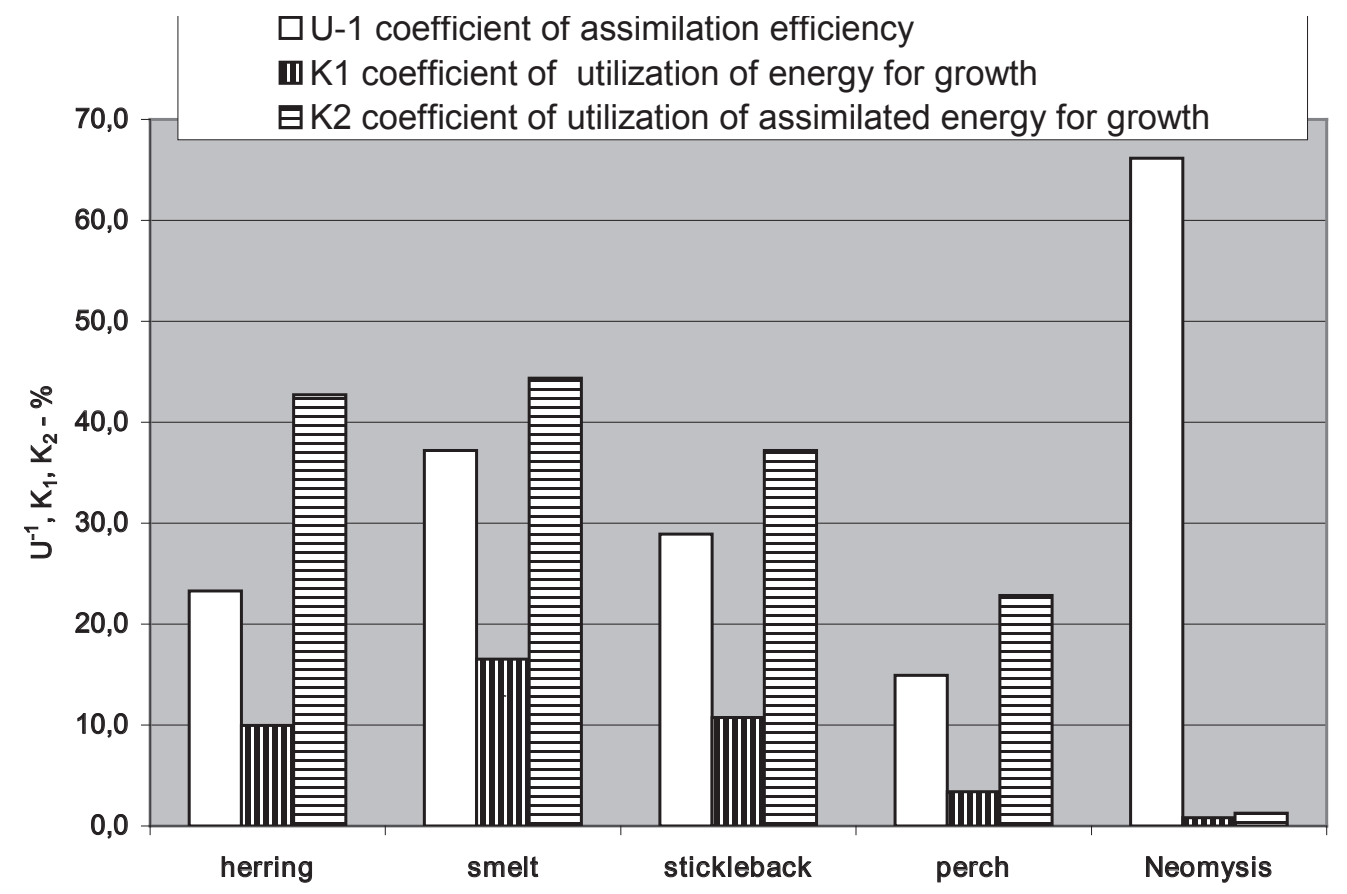

Fig. 8. The values of the efficiency of food assimilation $U^{-1}$, coefficient of utilization of energy for growth $K_{1}$ and coefficient of utilization of assimilated energy for growth $K_{2}$ in planktonic animals in the Vistula Lagoon

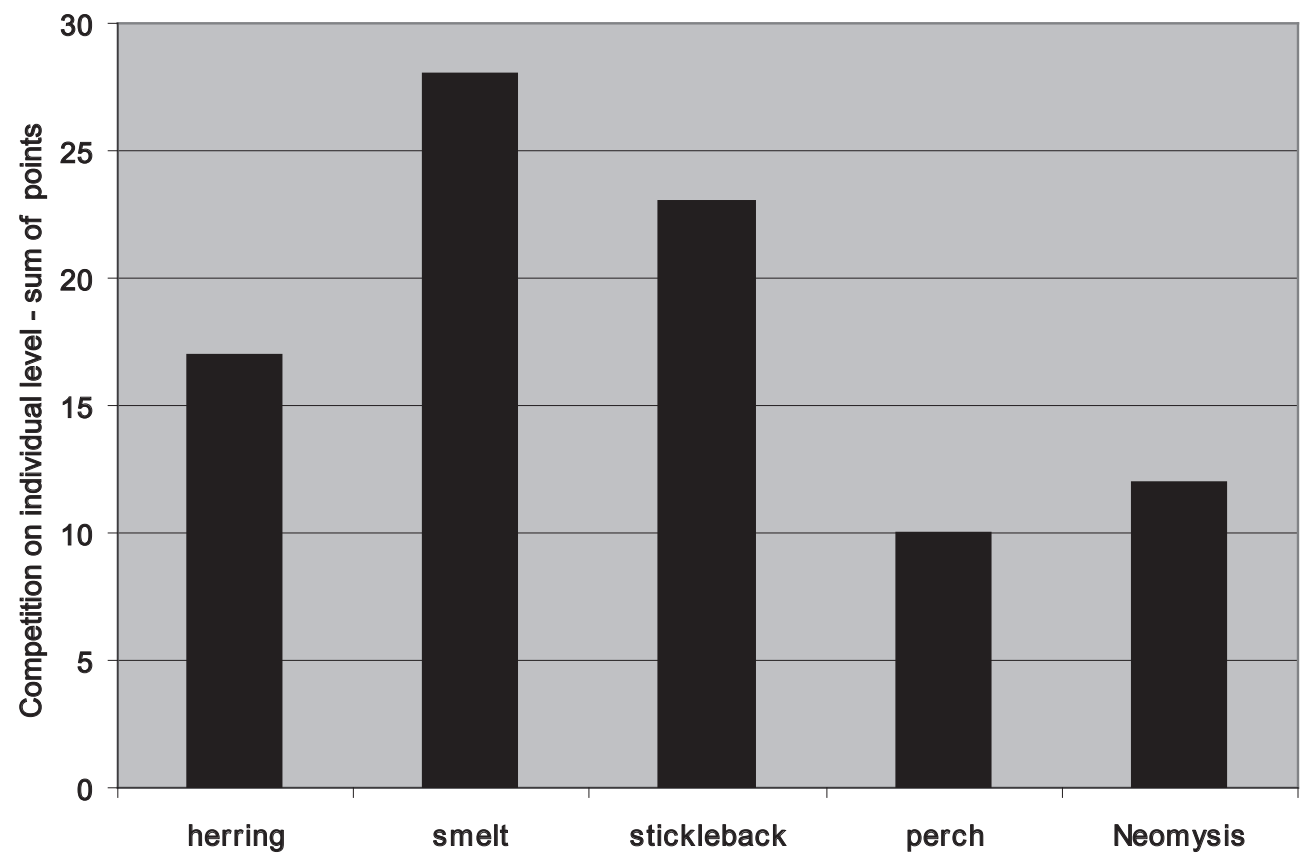

Fig. 9. Rank (as the sum of points) of macroplankton animals competing for food in the Vistula Lagoon in spring. 


\subsubsection{Population level}

Animal abundance ( $n \mathrm{~m}^{-3}$, literature data), daily consumption rate by individuals of particular species living in the unit of water volume ( $\Sigma C$ in $\left.\mathrm{J} \mathrm{m}^{-3} \mathrm{~d}^{-1}\right)$, and daily consumption rate by individuals of particular species living in the unit of water volume as a percent of the total food available $(C \%)$ were used as measures of population (or species) success in competition for food.

In terms of population abundance, that can be considered a measure of success in competition for food by animals living in plankton communities, the unquestionable winner was Neomysis, followed far behind by herring, smelt, stickleback, and perch (Fig. 10).

Both the highest daily consumption rate of individuals of parti-

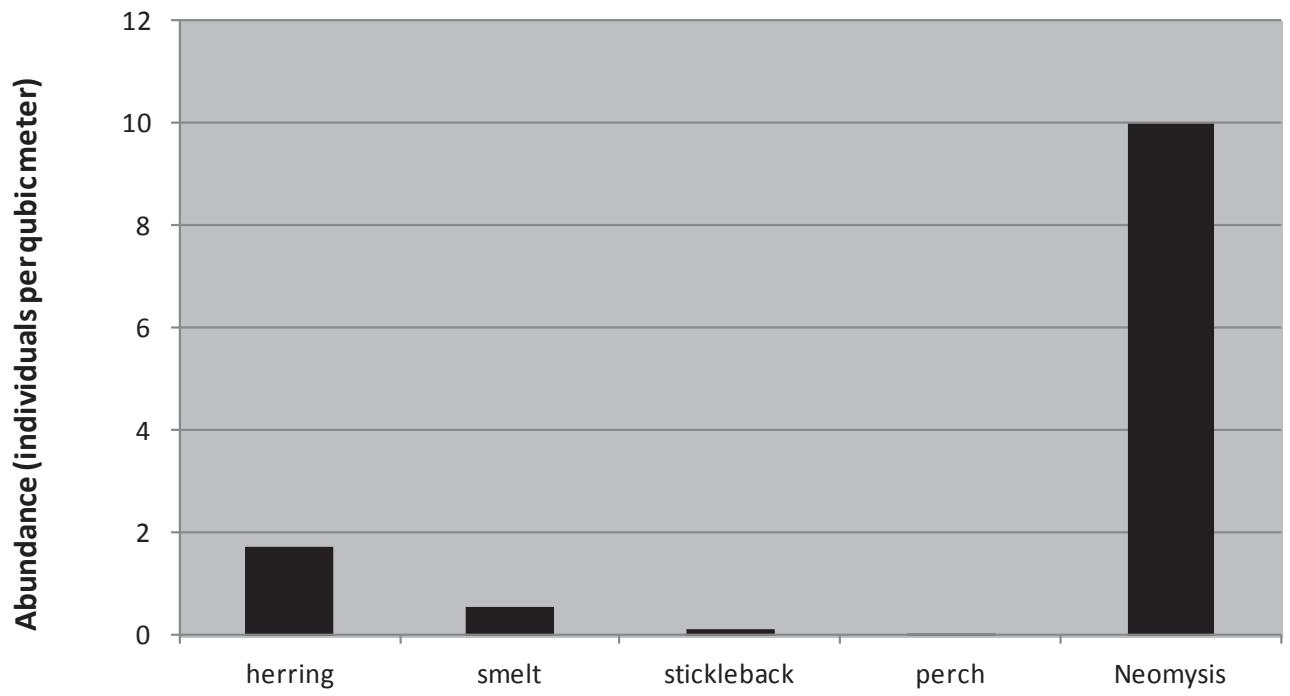

Fig. 10. Abundance of macroplankton animals in the pelagic zone of the Vistula Lagoon in spring.

cular species living in the unit of water volume $\left(\sum C\right)$ and the daily consumption rate of individuals of particular species living in the unit of water volume as a percent of the total food available $(C \%)$ were observed in Neomysis. The second was herring, then smelt, stickleback, and perch (Fig. 11). 


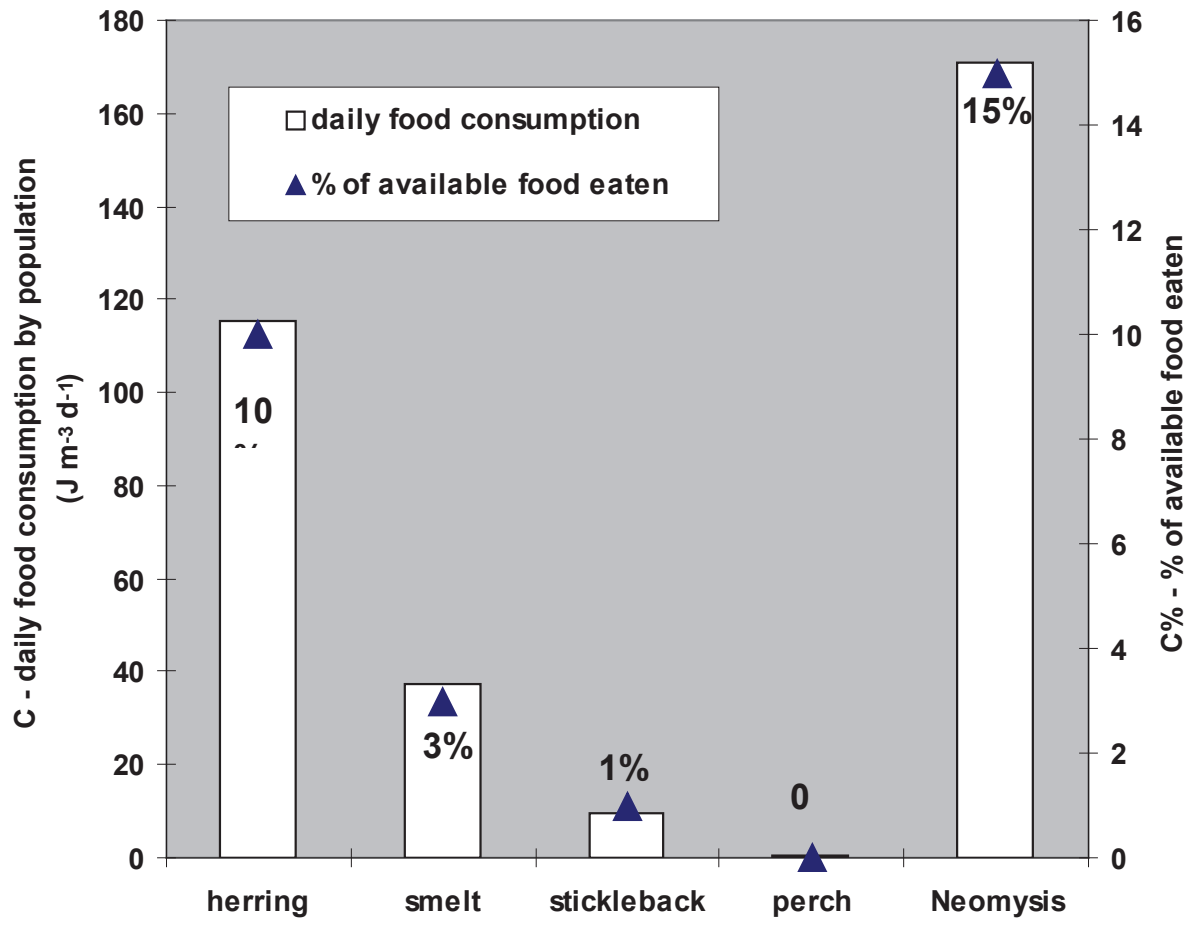

Fig. 11. Daily food consumption rate by the population $(\Sigma C)$ and per cent of the available food consumed by the population $(C \%)$ of macroplankton animals in the Vistula Lagoon in spring.

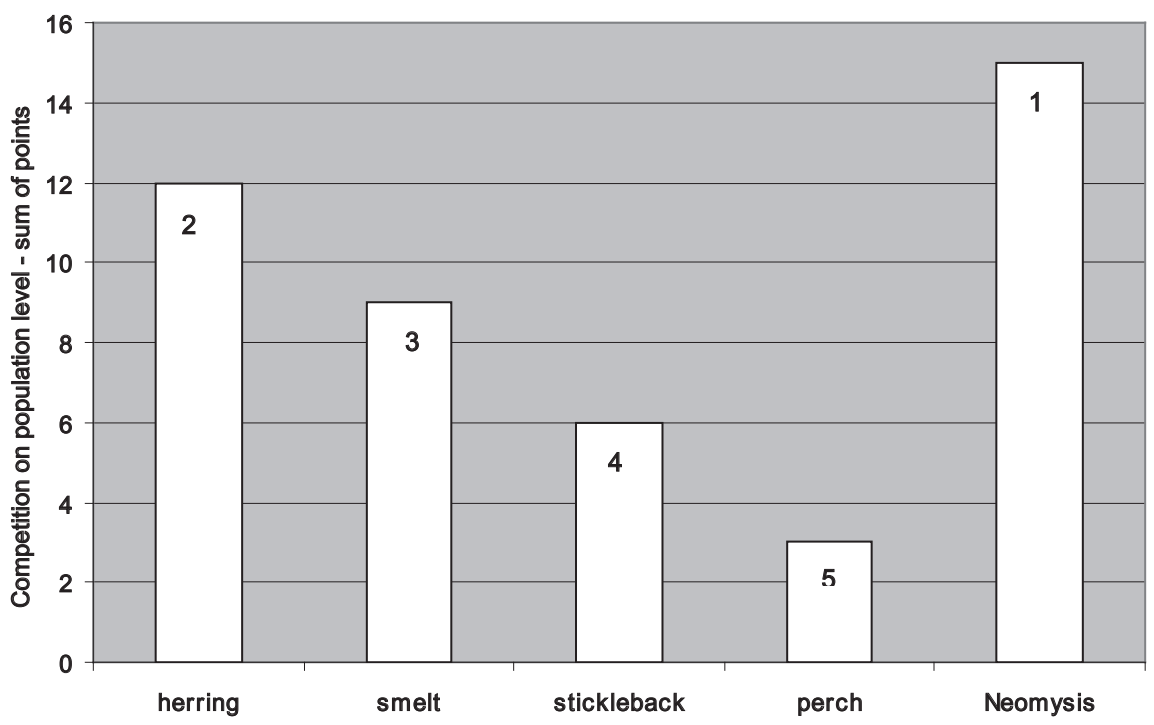

Fig. 12. Competition among macroplankton animals at the population level: sum of points (see text). Numbers in bars are ranks. 
Using the same scoring system as for competition at individual level, the unquestionable winner in competition for food at the population level was Neomysis (15 points of 15 possible, see Fig. 12).

\section{Discussion - who wins?}

The present results do not provide a clear indication which species is a superior competitor for food in the Vistula Lagoon zooplankton species community. Because competition occurs at the level of individuals rather than populations (Uchmański 2000, Grimm and Railsback 2005), a question arises why just Neomysis, despite their lowest food consumption (Fig. 7) and the lowest daily production rate, succeeded in reaching high population numbers (Fig. 11) and sum of daily food consumption by the population (Fig. 12)? The reason may be not only food consumption but also the assimilation of food, that is the coefficient of assimilation efficiency $\left(U^{-1}\right)$. This coefficient is about two fold higher in Neomysis in comparison with fish species. Coming back to competition at individual level, the greatest amounts of food per individual were consumed by early developmental stages of the stickleback, followed by the smelt, herring, perch, and Neomysis. Neomysis, as the only adult animal, consumed the smallest amounts of food (Fig. 7). However, when the individual daily production rate was considered, a different picture emerged - smelt was the winner (Fig. 8). The high value of the coefficient of utilization of assimilated energy for growth $\left(K_{2}\right)$ in smelt can compensate for a lower food ration. Kioeroboe et al. (1987) have even stated that in fish an efficient transformation of assimilated material to body mass (in other words a high $K_{2}$ ) should be favored by natural selection - and smelt is the winner in the competition for food, for life.

\section{References}

Bieńkowski P., 1990, Evaluation of methods of calculation of energetic value of organic matter from its elementary composition, Pol. Ecol. Stud. 16, 245-258. 
Chubarenko B., Margoński P., 2008, The Vistula Lagoon, in: U. Scheiwer (ed.), Ecology of Baltic coastal waters, Vol IIB, Ecological Studies vol 197, Springer, Berlin, Heidelberg, 167-195.

Colombo B., Baccanti M., Dutko B., 1988, Calculation of the heat value of solid and liquid, Fuels. Internat. Lab. 18: 1-2.

Connell J.H., 1975, Some mechanisms producing structure in natural communities: a model and evidence from field experiments, in: Cody L.M., Diamond J. (eds), Ecology and evolution of communities, Harvard University Press, Cambridge, 460-491.

Diamond J., Case T.J., 1986, Community ecology, Harper and Row, New York.

Dowgiałło A., 1975, Chemical composition of an animal's body and of its food, in: W. Grodziński, R.Z. Klekowski, A. Duncan A. (eds), Methods for ecological bioenergetics, Blackwell Scientific Publications, Oxford, 160-184.

Duncan A., Klekowski R.Z., 1975, Parameters of an energy budget, in: W. Grodziński, R.Z. Klekowski, A. Duncan A. (eds), Methods for ecological bioenergetics, Blackwell Scientific Publications, Oxford, 97-147.

Elliott J.M., Davison W., 1975, Energy equivalents of oxygen consumption in animal energetics, Oceologia (Berl.) 19: 195-201.

Fry F.E.J., 1947, Effect of the environment on animal activity, Publ. Ontario Fish. Res. Lab. 68, 1-62.

Fry F.E.J., 1957, The aquatic respiration of fish, in: M.E Brown, The physiology of Fishes, New York, Academic Press, 1-63.

Gause G.F., 1932, Experimental studies on the struggle for existence, Journal of Experimental Biology 9, 389-402.

Goldberg D.E., Barton A.M., 1992, Patterns and consequences of interspecific competition in natural communities: a review of field experiments with plants, Am. Natur. 139, 771-801.

Grimm V., Railsback S. F., 2005, Individual-based modeling and eco$\log y$, Princeton University Press, Princeton, Oxford.

Kamler E., 2003, Antarctic fishes: chemical composition of muscle, liver and food of two Notothenioids, Arch. Pol. Fisheries 11, 197-206. 
Kioeroboe T., Munk P., Richardson K., 1987, Respiration and growth of larval herring Clupea harengus: relation between specific dynamic action and growth efficiency, Mar. Ecol. Prog. Ser. 40, 1-10.

Klekowski R.Z., Opaliński K.W., Gorbunva N.N., 1980, Respiratory metabolism in early ontogeny of two Pacific flying fishes (Hirundichthys marginatus and Cheilopogon unicolor) and Pacific sardine (Sardinops sagax sagax), Pol. Arch. Hydrobiol. 27, 537-547.

Kleiber M., 1961, The fire of life. An introduction to animal energetics, J. Wiley, New York, London.

Krasovskaya N.V., 1998, Reproduction and abundance dynamics of the Baltic herring (Clupea harengus membras L.) in the Vistula Lagoon of the Baltic Sea, in: Proceedings of Symposium "Freshwater fish and the herring populations in the coastal lagoons", Sea Fish. Inst., Gdynia, 125-142.

Krasovskaya N.V., 2002, Spawning of Baltic herring in the Vistula Lagoon: effects of environmental conditions and stock parameters, Bull. Sea Fish. Inst. 155, 3-25.

Maciejewska K., Opaliński K.W., 2002, Daily energy requirement in the mysid shrimp Neomysis integer in the Vistula Lagoon, Bull. Sea Fish. Inst. 157, 19-31.

Maciejewska K., Opaliński K.W., Margoński P., 2001, Energy budget in early stages of smelt Osmerus eperlanus (L.), Bull. Sea Fish. Inst. $153,53-61$.

Naumenko E.N., 1998, Species composition, seasonal and long-term dynamics of zooplankton abundance and biomass in the Vistula Lagoon of the Baltic Sea, in: Proceedings of Symposium "Freshwater fish and the herring populations in the coastal lagoons", Sea Fish. Inst., Gdynia, 161-172.

Odum E.P., 1971, Fundamentals of ecology, W.B. Saunders Company, Philadelphia, Penn.

Odum E.P., 1992, Great ideas in ecology for the 1990s, BioScience 42, 542-545.

Opaliński K.W., Maciejewska K., Krajewska-Sołtys A., Fey D.P., 2004, Production and oxygen consumption in the early life stages 
of herring and smelt in the Vistula Lagoon (Baltic Sea), Bull. Sea Fish. Inst. 162, 13- 21.

Salt G. (ed.), 1984, Ecology and evolutionary biology: a roundtable on research, Am. Naturalist 122, 583-705.

Schoener T.S., 1983, Field experiments on intraspecific competition, Am. Naturalist 122, 240-285.

Solorzano Z., 1969, Determination of ammonia in natural waters by phenol-hypochlorite method, Limnol. Oceanogr. 14, 799-801.

Strong D.R.(Jr), Simberloff D., Abele L.G., Thistle A.B. (eds), 1984, Ecological communities: conceptual issues and evidences, Princeton University Press, Princeton.

Uchmański J., 2000, Individual variability and population regulation: an individual-based model, Oikos 90, 539-548. 